\title{
Qualitative Orientations to Readability Research: The Sociocultural Treats of Teenage Reading
}

\author{
Sarra Hadjeres \\ Canterbury Christ Church University \\ School of Language Studies and Applied Linguistics
}

\begin{abstract}
Readability research has been widely criticised for being quantitatively biased. Therefore, the need for more qualitative research paradigms was raised. In my research, I intended to examine the readability of texts in teenage readers' milieu. My research is qualitatively driven because I am interested in uncovering the factors that either impede or foster young readers' text comprehension. Therefore, readability in this research is discussed from a qualitative perspective. In this research, I tend to gain a good understanding of the text-reader relationship and see how both material and immaterial factors are interactively affecting and affected. The data were collected from various Algerian middle schools, with different geographical backgrounds, where qualitative research tools were implemented. Hence, Middle school teachers and learners were involved in semi-structured and focus group interviews and informal discussions. The data are analysed adopting a thematic analysis framework. Initial findings reveal that the readability of the text is not only linguistically defined but rather implied in a set of sociocultural agencies.
\end{abstract}

Keywords: Readability, teenagers, society, culture, Agency. 